\title{
Esquizofrenia e criatividade artística
}

\author{
Schizophrenia and artistic creativity
}

\author{
Ana Cristina Resende \\ Pontifícia Universidade Católica de Goiás, PUC-Goiás, Goiânia, Goiás, Brasil
}

\section{I rani I racema de Lima Argimon}

Pontifíca Universidade Católica do Rio Grande do Sul, PUCRS, Porto Alegre, Rio Grande do Sul, Brasil

\begin{abstract}
RESUMO
Este artigo constitui um estudo teórico sobre a esquizofrenia e a criatividade artística. O estudo foi baseado no levantamento da produção científica nas bases de dados Web of Science, PsyclNFO e Medline, dos últimos dez anos, utilizando as palavras-chave Schizophrenia e Creativity. A maioria dos estudos aponta que o mais provável é que a vulnerabilidade para a esquizofrenia manifeste diferentes vantagens criativas por causa de suas possíveis características perceptuais, cognitivas e de personalidade. Contudo a ideia de que distúrbios do espectro da esquizofrenia possam desencadear a criatividade artística não é defensável.
\end{abstract}

Palavras-chave: Esquizofrenia; Esquizotipia; Criatividade artística.

\begin{abstract}
This article constitutes itself as a theoretical study about schizophrenia and artistic creativity. The study was based on a survey of the scientific production in the databases Web of Science, PsyclNFO and Medline for the last ten years, using the key words Schizophrenia and Creativity. The majority of the studies points out that the most probable fact is that the vulnerability for schizophrenia manifests several creative advantages because of its possible perceptual, cognitive and personality characteristics. However, the idea of a spectrum of schizophrenia to trigger artistic creativity is not defensible.
\end{abstract}

Keywords: Schizophrenia; Schizotypy; Artistic creativity.

\section{I ntrodução}

A possível ligação entre loucura e criatividade tem sido uma fonte persistente de fascínio para a humanidade durante séculos. Na Grécia Antiga, Platão referiu-se à inspiração poética como loucura divina, enquanto Aristóteles chegou a afirmar que nunca houve um grande gênio sem uma dose de insanidade (ARISTÓTELES, 1998; Pessotti, 1995). Contudo, somente no século XIX, há mais ou menos duzentos anos, que a loucura passou a receber status, estrutura e significação psicológicos, tornando possíveis estudos mais sistematizados para 
verificar se realmente a criatividade artística demanda algum grau de distúrbio psíquico (FOUCAULT, 1984; PESSOTTI, 1995).

A partir de então, houve uma maior tendência a associar a criatividade no campo artístico com os transtornos psicopatológicos definidos de modo mais preciso. Expunha-se que a sobrecarga de produtividade mental que essas pessoas produziam, integrada com vivências demasiadamente dolorosas, acabava por conduzir a uma lenta, irreversível e progressiva deterioração psíquica. Acreditava-se que foi exatamente isso o que acontecera com Schumann, van Gogh, Tchaikovsky e Rachmaninoff e outros grandes artistas proeminentes (PORTER, 1990).

Na metade do século $X X$, aumentaram as investigações empíricas de forma mais sistemática para a suposta ligação entre criatividade artística e transtornos esquizotípicos, transtorno esquizofreniforme, esquizoafetivo, ou a esquizofrenia propriamente dita. Observou-se ainda uma incidência maior de transtornos psicóticos, transtornos do humor, transtornos de personalidade, comportamentos suicidas e abuso de drogas entre os artistas, como também uma maior incidência de traços dessas psicopatologias entre os familiares de artistas (ANDREASEN, 1987; ANDREASEN; CANTER, 1974; ANDREASEN; POWERS, 1975; BARRANTES-VIDAL, 2004; JAMISON, 1989; LUDWIG, 1992; 1994) Apesar de algumas limitações metodológicas nas pesquisas, como amostras muito pequenas, sendo várias investigações baseadas em estudo de casos, e falta de controle dos subtipos diagnósticos e da discriminação de sintomas, os pesquisadores notavam que a conexão entre instabilidade psíquica e potencial criativo era evidente.

Ainda que a criatividade artística possa estar presente em pessoas com os mais variados traços de personalidade, desde pessoas psiquicamente saudáveis até aquelas acometidas por distúrbios psicológicos, o objetivo desse artigo é fazer um recorte na revisão da literatura teórica e empírica, no campo da psicologia, dos estudos que, particularmente, investigaram a possível relação entre esquizofrenia ou esquizotipia e criatividade artística. Para isso, realizou-se uma busca nas bases de dados Web of Science, Psycl NFO e Medline, nos últimos dez anos, de 2000 a 2009, utilizando as palavras-chave schizophrenia e creativity. Ao total foram levantados 180 artigos, dentre os quais, após a leitura criteriosa dos resumos, foram selecionados 16 artigos que focavam o tema proposto. Dessa forma, esses artigos tornaram-se as principais fontes de referências para se realizar uma revisão a respeito do que se sabe acerca dessa intrigante relação entre esquizofrenia e criatividade artística.

A seguir, será feita uma breve exposição das definições dos construtos esquizofrenia, esquizotipia e criatividade artística. Posteriormente, serão expostos alguns estudos que podem ser úteis na compreensão das relações que se estabelecem entre esses construtos e, no final, 
serão feitas algumas considerações a respeito desses estudos, bem como se buscará uma maior elucidação do que se tem investigado a respeito da esquizofrenia e criatividade artística durante a última década no que tange à psicologia.

\section{Definição dos construtos esquizofrenia e criatividade artística}

No que diz respeito à esquizofrenia, trata-se de uma doença mental, geralmente crônica, que envolve uma predisposição genética que requer ativação intrapsíquica e interpessoal (PULL, 2005). Uma das formas de caracterizar seus sintomas é por meio dos três grupos de sintomas de Liddle (LIDDLE; BARNES, 1990), podendo o paciente apresentar preferencialmente os sintomas de um único grupo, ou manifestar quase todos os sintomas dos três grupos ao mesmo tempo. O primeiro grupo é constituído pelos sintomas positivos ou de distorção da realidade, que são manifestações novas, floridas e produtivas do processo esquizofrênico. Os principais sintomas positivos são as alucinações ou psedoalucinações auditivas e visuais, como também os delírios ou ideias delirantes de conteúdos persecutórios, autorreferentes ou de influência, além de comportamentos bizarros, ideias bizarras e produções linguísticas como os neologismos e parafasias (DALGALARRONDO, 2000).

O segundo grupo é composto pelos sintomas negativos, ou síndrome das deficiências psicomotoras, que se manifestam pelo empobrecimento global da vida psíquica e social do paciente. A pobreza do discurso, o embotamento afetivo, apatia, anedonia, avolição, autonegligência e lentificação psicomotora constituem os principais sintomas dessa síndrome. O terceiro grupo é identificado pelos sintomas de desorganização ou de distúrbio do pensamento, ou seja, comportamento pueril, fala desorganizada, déficits cognitivos e afeto lábil (DALGALARRONDO, 2000).

Os aspectos cognitivos - um conjunto de capacidades que habilitam os seres humanos a desempenhar uma série de atividades no âmbito pessoal, social e ocupacional, tais como: concentrar-se na leitura de um livro, aprender novas informações, solucionar problemas, realizar escolhas, manter uma conversa, entre outras - tendem a ser amplamente afetados na esquizofrenia. Dentre as funções cognitivas mais prejudicadas estão as funções executivas (habilidades de abstração e de flexibilidade conceitual envolvidas na solução de problemas), o QI (coeficiente de inteligência), a memória e a atenção, que são funções em grande parte associadas aos sintomas negativos e de desorganização da doença. De uma forma geral, todos esses aspectos cognitivos deficitários parecem ser características centrais no transtorno esquizofrênico (ABRAHAM; WINDMANN; 
MCKENNA; GUNTURKUN, 2007; ADAD; CASTRO; MATTOS, 2000; MONTEIRO; LOUZÃ, 2007).

A esquizotipia, ou transtorno de espectro esquizofrênico, ou ainda vulnerabilidade para a esquizofrenia, também citada em vários estudos que buscam entender qual é a possível relação entre esquizofrenia e criatividade, é considerada uma psicopatologia que foi derivada de maneira indutiva com base nos traços e sintomas encontrados na esquizofrenia (LENZENWEGER, 2005). Dessa forma, os sintomas positivos e negativos da esquizotipia são congruentes com os sintomas positivos e negativos da esquizofrenia, porém com intensidade e duração menores que os sintomas da esquizofrenia.

A esquizotipia positiva está associada à excentricidade na fala e no comportamento, a experiências incomuns, bem como a um fácil engajamento em pensamentos intuitivos, mágicos e até mesmo divergentes (FOLLEY, 2006). Barrantes-Vidal, Lewandowski e Kwapil (no prelo) observaram que todas essas características da esquzotipia positiva também levam a prejuízos no ajustamento social e nas atividades e interações acadêmicas das pessoas por eles estudadas, mas nada comparado ao retraimento ou isolamento social observado nas pessoas com traços esquizotípicos negativos. Os sintomas negativos estariam mais voltados para a anedonia, avolição, ausência de amigos íntimos, embotamento afetivo, isolamento social (ROSS; LUTZ; BAILLEY, 2002).

No que tange à criatividade, ela tem sido considerada há vários anos como o misterioso traço que explica a extraordinária capacidade dos gênios. No entanto trata-se de um construto definível e mensurável, mas que ainda demanda mais investigações científicas para sua melhor definição operacional. O que parece central em qualquer uma de suas definições é o elemento de originalidade, que se refere à predisposição para gerar respostas novas e pouco comuns. Outras dimensões pertinentes constituem a relevância das ideias e a capacidade para o pensamento divergente, fluente, flexível e aberto a novas experiências e possibilidades, que são fatores que contribuem para a criação de algo de valor permanente e importante para a humanidade (ABRAHAM, et al., 2007; Folley, 2006).

Há estudos que defendem a ideia de que qualquer indivíduo apresenta certo grau de habilidades criativas, que podem ser desenvolvidas e aprimoradas por meio de treinamento e prática. Nesse ponto de vista, ressalta-se a importância da preparação, da dedicação, da persistência e do esforço consciente da pessoa, da sua autoconfiança, do seu conhecimento amplo de uma área do saber para se chegar aos estágios de inspiração e elaboração do processo criativo. Observa-se ainda que o contexto sócio-histórico-cultural, os aspectos do ambiente de trabalho ou estudo, o papel da educação e da sociedade são fatores importantes que podem propiciar ou limitar 
a capacidade da pessoa ser criativa ou de obter resultados criativos em seu desempenho (ALENCAR, 1995; RAVEN, 2002).

No caso da criatividade artística, entende-se que se trata da capacidade de produzir algo que seja reconhecido pelas pessoas da sociedade como original e relevante no campo das artes plásticas, seja na escultura, na pintura ou na arquitetura, das artes rítmicas ou fonéticas como na música, na dança e na literatura, das artes cênicas, como teatro, cinema e circo, ou de outras artes como no desenho, na gravura, na fotografia e na arte digital.

\section{Esquizofrenia e criatividade artística na última década}

Um contato breve com um paciente com esquizofrenia, internado em um hospital, na fase de remissão dos sintomas da doença, mas ainda ativos, é suficiente para revelar que a pessoa nesse estado é bastante diferente de uma pessoa artisticamente criativa. Esses pacientes estão nitidamente vivendo em outra realidade bastante idiossincrática, quase sem comunicação com o mundo ao seu redor, muitas vezes com respostas emocionais incongruentes com a situação e com comportamentos bizarros, repetitivos e estereotipados. O pensamento é quase sempre grotesco, às vezes com manifestações de delírios ou alucinações, sem diferenciar informações importantes daquelas irrelevantes.

Por outro lado, alguns artistas revelam pensamentos e condutas um pouco excêntricos. Alguns se afastam das pessoas e se colocam à margem da sociedade para buscar em si mesmos a inspiração para o seu trabalho, interpretam o mundo ao seu redor de modo bastante incomum e, muitas vezes, supervalorizam aspectos da realidade que passam despercebidos pela maioria das pessoas. Além do mais, alguns artistas frequentemente relatam experiências perceptivas e sensoriais extravagantes, tais como associações de ideias vagas, amplo foco de atenção ou capacidade de perceber várias coisas ao mesmo tempo e se interessar, simultaneamente, pelas mais variadas solicitações sensoriais e capacidade para se conectar com novas informações ou até mesmo com vozes interiores (CASTELO FILHO, 2004; RICHARDS, 2001).

Todas essas características, mesmo que não tenham o aspecto mórbido do transtorno esquizofrênico, propiciam as associações que se têm estabelecido entre pessoas com esquizofrenia, ou predisposição para tal enfermidade, e criatividade artística. Valendose dessas semelhanças, os estudiosos começaram a investigar o grau de incidência de esquizofrenia entre os artistas e seus familiares e entre aqueles que não são artistas, verificando se traços dessa doença poderiam predispor a pessoa a revelar talentos artísticos, e se 
pessoas criativas teriam pontuações mais elevadas em testes psicológicos que avaliam traços psicóticos.

Nesse sentido, a literatura científica atualmente fornece um corpo de evidências sustentando a noção de que a esquizofrenia, ou a esquizotipia, pode estar associada à criatividade artística, seja entre pintores, músicos, escritores ou escultores. De fato, estudos recentes sugerem que algo do funcionamento psíquico de pacientes com esquizofrenia, ou esquizotípicos, esteja relacionado com algo do funcionamento psíquico de pessoas altamente criativas ( $A B R A H A M$, et al., 2005; ABRAHAM, et al., 2007; BARRANTES-VIDAL, 2004; BURCH; PAVELIS; HEMSLEY; CORR, 2006; FISHER, et al., 2004; FOLLEY, 2006; HELLING; OHMAN; HULTMAN, 2003; HOYT; 2003; MILLER; TAL; 2007; NETTLE; 2006; NETTLE; CLEGG, 2006; O'REILLY; DUNBAR; BENTALL, 2001; OTSUKA; SAKAI, 2004; RUBINSTEIN, 2008; RYBAKOWSKI, et al., 2006; SASS, 2000-2001), embora, de um modo geral, todos admitam que os processos psíquicos de uma personalidade patologicamente estruturada parecem ser distintos dos processos psíquicos de uma personalidade artisticamente criativa.

Estudos comprovam que a esquizofrenia é, em grande parte, genética, e que a fertilidade é diminuída entre os pacientes com esse transtorno, especialmente no sexo masculino, quando comparada com pessoas saudáveis da população em geral (APA, 2002; TERZIAN; ANDREOLI, et al., 2006). Com base na questão da menor taxa de fertilidade nesses pacientes e da porcentagem, mais ou menos constante, de incidência dessa doença em praticamente todas as culturas (1\% da população), Brune (2004) levantou um questionamento: por que, apesar da desvantagem reprodutiva, a seleção natural permitiu que os genes que aumentam a probabilidade de sofrer desse transtorno tão devastador se mantivessem no genoma humano? Para responder a esse enigma o autor buscou uma série de hipóteses evolutivas que permitem observar o paciente de diferentes ângulos, embora essas proposições não expliquem empiricamente a correlação esquizofrenia e criatividade. Dentre as hipóteses, uma supõe que, provavelmente, no âmbito social, deve existir uma vantagem compensatória em alguns portadores da doença ou em alguns de seus parentes de primeiro grau, que geralmente apresentam traços esquizotípicos, desenvolvendo uma maior predisposição para a criatividade e comportamentos xamanísticos.

Inclusive estudos mais antigos apontaram que parentes próximos, até segunda geração, de pacientes psicóticos eram duas vezes mais prováveis de estar envolvidos em empreendimentos que exigiam alta criatividade (KARLSSON, 1970), como também eram mais bem sucedidos em profissões acadêmicas e profissões artísticas (KARLSSON, 1983). Estudos um pouco mais atuais mostram indícios 
de maiores realizações criativas em famílias de indivíduos com doença mental e aumento da incidência de doenças mentais entre os irmãos de pessoas altamente criativas (KARLSSON, 2001).

Por sua vez, Netlle (2001) também presumiu que, à primeira vista, a esquizofrenia e as psicoses em si realmente não justificam as suas presenças no mundo. Mas, ao buscar entender essas psicopatologias como variações anormais da criatividade humana, dados alguns indícios empíricos, o autor deduziu que, sem essa contrapartida do gênio, o mundo ainda estaria engatinhando, se é que teria existido alguma vez algo denominado civilização. Nesse sentido, provavelmente, o preço da genialidade entre os seres humanos seja alguns transtornos psicopatológicos.

É importante salientar que estudos empíricos genéticos mais recentes também apoiam as correlações entre esquizofrenia, ou disponibilidade para este transtorno, e criatividade envolvendo algum tipo de vantagem ou evolução genética adaptativa dos genes. Nas análises de Bachner-Melman, et al. (2005), Crespi, Summers e Dorus (2007), como também de Reuter, Roth, Holve e Hennig (2006), embora ainda não tenham desvendado o tal enigma genético e nem dado informações diretas sobre a forma como as pressões seletivas a nível fenotípico pode ter impactado a evolução destes genes, há evidências de que ocorre uma evolução adaptativa dos genes subjacentes a esquizofrenia quando se estuda os vínculos genéticos entre os genes que predispõe o risco de esquizofrenia e os genes responsáveis pela criatividade.

No âmbito da avaliação psicológica, ainda no sentido de investigar a existência desse enigma evolutivo em torno da persistência da esquizofrenia, já que é substancialmente hereditária e associada a baixos níveis reprodutivos, tem-se o estudo empírico de Nettle e Clegg (2006). O estudo envolveu 425 adultos britânicos: artistas no campo das artes plásticas, poetas e pessoas da população geral. Os resultados dessa investigação, feita por meio de questionários (Inventário de Esquizotipia O'LIFE, questões econômicas, sóciodemográficas, da história psiquiátrica do sujeito e de sua família, questões a respeito do interesse em atividades criativas e o grau de envolvimento nessas atividades, além de questões relativas aos relacionamentos sexuais) foram: pessoas com experiências incomuns e que se dedicavam seriamente, ou profissionalmente, às atividades artísticas declararam uma quantidade significantemente maior de parceiros sexuais; pessoas que apresentavam maior nível de impulsos não-conformista também declararam um número significativamente maior de parceiros sexuais; e pessoas com níveis mais elevados de desorganização cognitiva e anedonia, quase sempre não estavam envolvidos em qualquer tipo de atividade criativa e possuíam significantemente menos parceiros sexuais. 
De uma forma geral, os resultados do estudo dos autores apontaram três aspectos. Primeiro, houve uma correlação direta entre atividades criativas e número de parceiros. Segundo, os artistas apresentaram altos escores em experiências incomuns e inconformismo assim como geralmente pessoas com traços esquizotípicos apresentam. Terceiro, os artistas se diferenciavam de resultados de pacientes esquizotípicos apenas por apresentarem baixos escores em anedonia (NETLLE, 2006). Sugeriu-se, então, que indivíduos com bons recursos psicológicos podem canalizar as experiências incomuns e os impulsos não-conformista para produções criativas e para comportamentos adaptativos, enquanto que aqueles em condições gerais pobres podem sucumbir-se aos efeitos desorganizadores dessas características e desenvolver transtornos psiquiátricos. Se este modelo de explicação estiver correto, os componentes da esquizotipia funcionariam como a capacidade de um organismo para sobreviver e transmitir o seu genótipo para a sua descendência. Por outro lado, a anedonia poderia ser a condição essencial que diferencia traços positivos e negativos da esquizotipia. Os autores concluem que os seus resultados constituem a evidência mais direta de que a escolha do companheiro está ligada à criatividade, e a criatividade está relacionada a esquizotipia que, por sua vez, tem alguma relação com a esquizofrenia. Os autores ainda sugerem que para compreender melhor como a esquizotipia correlaciona-se com o comportamento de ter mais parceiros sexuais seria interessante verificar se isto está relacionado a uma maior rotatividade dos relacionamentos, ou menos de tempo de intervalo entre um relacionamento e outro.

Miller, et al. (2007) discordam dessa concepção de que os genes que predispõem a pessoa a distúrbios de espectro esquizofrênico persistam na população em função dos possíveis benefícios da criatividade de uma esquizotipia positiva em parentes não-psicóticos. Os autores avaliaram a criatividade (por meio de seis tarefas verbais e oito tarefas de desenhos), a esquizotipia (SPQ scale), os traços de personalidade (NEO-FFI Big Five Model) e a inteligência geral (Matrizes Progressivas de Raven) de 225 estudantes de graduação. Seus resultados apontaram que o fator abertura para experiência e a inteligência, e não a esquizotipia propriamente dita, estavam diretamente relacionadas com a criatividade. Entende-se por abertura para experiência a flexibilidade de pensamento, fantasia e imaginação, abertura para novos acontecimentos e interesses culturais. Logo, seus resultados são consistentes com outros estudos que apontam a correlação positiva entre abertura para experiência e criatividade (CARSON; PETERSON; HIGGINS, 2005; DOLLINGER; URBAN; JAMES, 2004), e outros que indicam que a esquizotipia não é diretamente preditiva de criatividade (BURCH; HEMSLEY; PAVELIS; CORR, 2006). 
No sentido de investigar o traço esquizotípico e a saúde mental em um grupo de artistas, que foi comparado com outros dois grupos (de pacientes com esquizofrenia e de pessoas da população em geral), Nettle (2006), mediante os mesmos instrumentos utilizados no estudo já citado de Nettle e Clegg (2006), observou que os artistas apresentavam níveis de experiências e ideias incomuns tão elevados quanto o grupo de pacientes com esquizofrenia. Contudo os artistas não compartilhavam o mesmo nível elevado de esquizotipia negativa que os pacientes esquizofrênicos revelavam. Por meio desse estudo, obteve-se uma validade adicional para a questão já anteriormente contemplada em outras pesquisas (BURCH, et al., 2006; FISHER, et al., 2004; NETTLE; CLEGG, 2006): os altos escores em esquizotipia positiva correlacionam-se com criatividade artística e, ao mesmo tempo, correlaciona-se com alta vulnerabilidade para a esquizofrenia quando esse alto escore de esquizotipia positiva vem acompanhado de altos escores em esquizotipia negativa.

Ao compararem uma amostra de artistas visuais com outra amostra de não-artistas, Burch et al. (2006), usando testes de criatividade e de personalidade, encontraram mais traços esquizotípicos positivos e desorganizados (discursos vagos e imprecisos) no grupo de artistas. Ou seja, os artistas eram mais abertos às novas possibilidades, apresentavam mais pensamentos divergentes, ideias incomuns e respostas de indesejabilidade social. No geral, os resultados encontrados pelos autores sugeriram uma maior predisposição para desajustes psicológicos em pessoas que se sobressaíam pelas suas habilidades artísticas.

Outros pesquisadores que apontaram para uma possível ligação entre esquizofrenia e criatividade foram Carson, Peterson e Higgins (2003). Por meio de uma investigação utilizando testes de criatividade, de inteligência, de personalidade e tarefas que mensuram a inibição latente, os autores demonstraram que as pessoas criativas do estudo tinham baixos níveis de inibição latente, ou seja, eram mais receptivas a estímulos externos; elas continuavam em contato com as informações extras que chegavam constantemente do ambiente e se mantinham atentas às novas possibilidades, como também apresentaram coeficientes de inteligência mais elevados. Já as pessoas, de um modo geral, tendiam a ignorar estímulos que pareciam inúteis ou irrelevantes para suas necessidades, com predomínio de níveis intelectuais medianos. Concluiu-se com esta investigação que, quanto menor a inibição latente ou controle inibitório, maior seria a criatividade.

No final, Carson, et al. (2003) discutiram que a baixa inibição latente associada à criatividade também está presente na esquizofrenia. Nessa enfermidade é possível observar a criatividade em seus estágios iniciais de desenvolvimento, porém, acompanhados de grande introspecção, de idéias místicas e de experiências religiosas 
em razão de alterações químicas no cérebro. Outro problema da esquizofrenia é que, com uma memória operacional prejudicada e com menores coeficientes de inteligência, os pacientes se afogam em uma torrente de significados, interpretações e emoções, não conseguindo discriminar informações importantes de informações acessórias, à medida que a doença progride. Dessa forma, parece que baixos níveis de inibição latente e elevada flexibilidade do pensamento podem predispor à esquizofrenia sob determinadas condições e, sob outras condições, podem levar ao desenvolvimento de uma criatividade brilhante. Portanto, segundo os autores, os resultados do estudo sustentam a teoria de que indivíduos altamente criativos e aqueles com predisposição à esquizofrenia podem possuir algumas semelhanças neurobiológicas, talvez geneticamente determinadas.

Rubstein (2008) investigou a criatividade de três grupos de pacientes: pacientes com esquizofrenia crônica; pacientes com depressão maior e transtorno de ansiedade; e pacientes com transtorno de personalidade (grupos A e B). Para isso, os participantes foram entrevistados e submetidos a um teste de criatividade (Tel-Aviv Criativity Test - TACT). De uma forma geral, os pacientes com esquizofrenia apresentaram o menor grau de criatividade, especialmente no fator fluência conceitual. No que diz respeito à originalidade, não houve diferenças significativas entre os três grupos. O autor alegou que os participantes do grupo de esquizofrênicos eram pacientes crônicos, em que havia o predomínio de sintomas negativos, aqueles sintomas não produtivos da doença, que são comuns em pacientes que já sofreram diversos surtos psicóticos e já foram internados várias vezes ao longo de sua vida. De qualquer forma, era de se esperar que a deficiência verbal e o maior prejuízo geral na personalidade se encontrassem no grupo de esquizofrenia, já que é o distúrbio psicótico comumente mais intenso e desestruturante do que os demais tipos de transtornos psíquicos

Deve-se ponderar que, na fase ativa de um transtorno esquizofrênico ou nas fases de intensa agitação ou depressão, a pessoa não consegue se organizar a ponto de produzir uma obra de arte. A franca esquizofrenia desestrutura e bloqueia a pessoa, inviabilizando qualquer produção criativa (SASS, 2000-2001). Abraham, et al. (2007), ao estudarem funções executivas e desempenhos criativos entre um grupo de pacientes com esquizofrenia e um grupo controle, distinguiram que algumas funções cerebrais executivas pobres, como o baixo controle inibitório, podem ser vantajosas na habilidade de dar resposta criativa, mas só até certo ponto, pois as perturbações graves são prejudiciais no desempenho criativo. De acordo com os achados da pesquisa dos autores, seria inadequado pensar que 0 desempenho pobre em algumas ou todas as funções executivas poderia estar relacionado com a originalidade do pensamento criativo 
ou com a habilidade de gerar respostas novas. Os autores ainda sugerem que uma reconceitualização dos mecanismos subjacentes nas funções criativas seria necessária para se compreender os seus diversos aspectos.

Obviamente parece absurdo que qualquer transtorno psicopatológico grave, como a esquizofrenia, esteja diretamente relacionado com criatividade e genialidade no campo das artes, embora exista toda uma tradição histórico-cultural e científica que promove essa ligação, avalia Barrantes-Vidal (2004). A resposta do autor para esse paradoxo é que os distúrbios devem ser considerados dentro uma visão dimensional, em que a diferença entre normalidade e psicopatologia esteja mais no aspecto quantitativo do que no qualitativo. Por exemplo, a ansiedade - uma função adaptativa e necessária que sinaliza um perigo iminente - quando em excesso pode tornar-se bastante disfuncional e desencadear um transtorno de ansiedade. Da mesma forma, a esquizotipia, a princípio, pode estar relacionada com características vantajosas que predispõem a pessoa à criatividade, mas em uma dimensão exagerada pode levar ao devastador transtorno esquizofrênico.

Não basta, entretanto, somente a compreensão dessa dimensionalidade dos distúrbios psíquicos, pois, além da intensidade ou quantidade, eles também se desenvolvem dentro de uma série de contextos. É possível que traços de personalidade subjacentes a esses distúrbios compartilhem algumas características cognitivas, emocionais e biológicas. A presença da predisposição para esquizofrenia em si não garante a criatividade artística. BarrantesVidal (2004) enfatiza que são necessários outros fatores que favoreçam os processos criativos, como as características individuais (inteligência e persistência, por exemplo) e fatores ambientais (como meio sociocultural e estimulação).

Considerando a questão do ambiente sociocultural, Sass (2000-2001) alegou que as noções centrais de criatividade no modernismo e pósmodernismo estão intimamente relacionadas aos traços esquizotípicos, o que propicia as tendências esquizotípicas assemelharem-se mais às sensibilidades artísticas no mundo contemporâneo do que os outros tipos de transtornos psíquicos. De um lado, têm-se os transtornos de espectro esquizofrênico, que se caracterizam por certa alienação, desprezo por convenções sociais, fluidez do pensamento, retraimento e apatia, perda da noção de tempo e espaço, intensa autoconsciência em que o sujeito se desapega das formas normais de contato com o mundo/objetos e se torna ele mesmo o objeto, intensa autorreferência, autocrítica e intelectualização disfuncionais, bem como incongruência das respostas emocionais, às vezes expressas por risos infundados.

Do outro lado, tem-se o estilo moderno e pós-moderno de criatividade artística, com uma estreita afinidade com essa 
psicopatologia. Essa nova arte é conhecida como a antiarte, que usa a deformação, a fragmentação, a abstração, o grotesco e a incongruência para se definir como arte (GESOMINO, 2008). É a arte que abandona os museus, as galerias, os teatros e é lançada nas ruas com outra linguagem, dando valor artístico à banalidade cotidiana e desvalorizando a obra e o autor, sendo altamente debochada, contraditória, sem normas e regras, buscando o efeito chocante e o efeito desconcertante das perspectivas em colapso. Essa nova arte é mais pautada nos exageros, nas superposições, nos automatismos mentais, com intensificação da autocrítica, do autoquestionamento, da ironia, das paródias e do distanciamento emocional. Segundo Gesomino (2008), o artista se torna desprovido de uma identidade fixa, essencial ou permanente.

De acordo com Pelbart (1989), evidências entre distúrbios psicóticos e criatividade artística, particularmente se referindo às formas como se comunicam com os demais, convergem: grandes obras de eminentes artistas como Hõlderlin, Nerval, Artaud, Gauguin, Byron, Tolstoi, Munch além dos já citados Schumann, Vicent van Gogh, Tchaikovsky e Rachmaninoff e vários outros; exposições realizadas por instituições psiquiátricas que testemunham a vitalidade e a criatividade até mesmo de pacientes cronificados por anos de hopitalizações; o Museu do Inconsciente no Rio de Janeiro; a exposição intitulada Arte e Loucura acorrida em São Paulo; o trabalho de certos profissionais da área psiquiátrica, especialmente dos terapeutas ocupacionais, que fundamentam a produtividade criativa dos pacientes; as várias obras de qualquer Bienal, que lembram ruínas e destruições e incitam perplexidades que de outras formas não seriam tão marcantes. Nesse último sentido, têm-se o trabalho citado por May (1992), em que os artistas enfeitaram um automóvel enferrujado com os intestinos e o sangue de uma vaca e o colocaram como natureza morta, numa rua de Nova Iorque. Em todos esses exemplos parecem se revelar o estado de choque dos artistas e da sociedade na qual eles funcionam como porta-vozes e que, de qualquer forma, mobilizam reações no público, instigam insights a respeito das interações interpessoais no mundo de uma maneira que foge dos padrões mais comuns de comunicação do que se pensa e sente.

Sendo assim, Sass (2000-2001) entende que, atualmente, o que é considerado uma sensibilidade artisticamente criativa tem muitas características subjacentes aos traços de um transtorno correlato à esquizofrenia. Tanto a arte moderna e pós-moderna quanto os distúrbios do tipo esquizofrênico são bem pouco convencionais e, às vezes, tendem a ter a bizarrice como característica central. Além disso, essa capacidade de criar algo totalmente novo no universo depende dessa capacidade de afastar-se e de desapegar-se da perspectiva convencional, uma habilidade que, segundo o autor, é 
alcançada mais facilmente por uma pessoa com uma orientação até certo ponto esquizotípica. Nesse sentido, as pessoas com traços esquizotípicos podem ter maior afinidade com a concepção de arte no mundo atual e podem ter mais oportunidade de serem aceitas ou reconhecidas. I sso não quer dizer que os esquizotípicos são mais numerosos na população de pessoas criativas. Na verdade, as pessoas criativas podem possuir os mais diferentes traços de personalidade. Isso significa apenas que o êxito criativo de pessoas com traços esquizotípicos pode ser comum, pelo menos dentro desse contexto ou período pós-moderno.

A maioria dos estudos sobre esquizofrenia e criatividade artística apresentados nesse artigo, por meio de investigações em grupos clínicos (pacientes com esquizofrenia ou com transtornos de espectro esquizofrênico) e não clínicos (estudantes universitários, artistas, pessoas da população em geral), incidiram mais sobre os traços esquizotípicos do grupo de sintomas positivos, do que sobre a esquizofrenia em si. Ou seja, diante de todos os argumentos aqui relatados, o que parece mais provável é que a vulnerabilidade para a esquizofrenia, especialmente no que tange aos sintomas positivos, e não o transtorno em si, manifesta diferentes vantagens criativas, possivelmente por causa de suas características perceptuais, cognitivas e de personalidade. Por exemplo, é comum no espectro positivo da esquizofrenia a pessoa estar mais propensa à introversão, à inabilidade e ansiedade sociais, à excentricidade e ao engajamento em pensamentos intuitivos e mágicos e, nesse sentido, ela tem mais possibilidade de demonstrar seu potencial criativo de modo mais relaxado e menos pressionado socialmente. Aliás, o contexto moderno e pós-moderno das criações artísticas, com sua linguagem exagerada, impactante, irônica e fragmentada se configura, em parte, como um contexto esquizotípico (GESOMINO, 2008; SASS, 2000-2001). As pessoas com esses traços esquizotípicos poderiam engajar-se em atividades criativas por prazer, e não por necessitar de plateia ou de autopromoção. Contudo a idéia de que distúrbios do espectro da esquizofrenia possam desencadear a criatividade artística não é defensável.

\section{Considerações Finais}

Com base no que foi exposto, observa-se que ainda não existem investigações empíricas que comprovam definitivamente que esquizofrenia esteja diretamente relacionada à criatividade artística. Por outro lado, também não existem estudos empíricos que comprovem, de forma convincente, que não existe qualquer associação entre ambos. 
Acredita-se que esquizofrenia e criatividade artística sejam duas realidades que se movem em diferentes contextos e correspondem a diferentes definições. Cada uma tem a sua individualidade, que se constrói sobre uma clínica e sobre uma estética bem diferente uma da outra. Porém a complexidade dessas duas condições pode sobrepor-se a algumas características de funcionamento semelhante e evidenciá-las. Contudo tem-se que conduzir o assunto respeitando a distância que existe entre esses dois construtos (esquizofrenia e criatividade artística).

Embora esses construtos não estejam necessariamente correlacionados, as pesquisas atuais revelam que traços de transtorno de espectro esquizofrênico, e não a doença em si, como também o contexto moderno e pós-moderno das criações artísticas favorecem as pessoas com esse espectro, especialmente os traços de sintomas positivos de esquizotipia, a serem reconhecidas como criativas no campo das artes. Em contrapartida aos sérios prejuízos que a esquizofrenia geralmente provoca na vida do indivíduo, da família e da sociedade, algumas pesquisas têm indicado que na família desses pacientes existem parentes próximos, com traços esquizotípicos que, em proporção duas vezes maior do que na população em geral, estão envolvidos em empreendimentos e profissões artísticos e que exigem elevados níveis intelectuais.

A importância desse artigo teórico é que ele salienta uma peculiaridade na esquizofrenia, que é a criatividade artística, e, ao mesmo tempo, agrupa informações úteis que possam apontar por onde caminham as investigações sobre esse tema intrigante, que foi herdado desde a Grécia antiga, quando se relacionava loucura e criatividade. Outro aspecto interessante desse artigo, embora secundário, é que ele acaba abordando, mesmo que superficialmente, as diferentes configurações do pensamento criativo, o que é essencial dada a natureza multifacetada da criatividade, que parece ser amplamente influenciada pelas mais diversas variáveis cognitivas e de personalidade tais como: abertura para experiência, baixa inibição latente, pensamento divergente, mágico e intuitivo, inteligência, indesejabilidade social dentre outras.

O construto criatividade, mesmo que esteja sendo estudado há algum tempo, continua bastante controverso, ainda mais quando se trata de estudar a criatividade artística. Além do mais, observou-se que o estudo do processo que desenvolve habilidades criativas em grupos psiquiátricos é um método eficiente de investigação que pode elucidar elementos do processo criativo, seja ele cognitivo, neurológico ou comportamental, que pode operar na patogênese da doença, como também elementos que podem ser comuns em todos os indivíduos.

Finalmente, considera-se que, embora nenhum dos estudos abordados tenha feito referência à questão da adequada percepção da realidade, ou capacidade de manter o contato com a realidade, 
como sendo um aspecto importante que diferencia uma mente criativamente brilhante de uma mente patologicamente extravagante, entende-se que este também seja um ponto digno de nota na discussão do tema desse artigo. Em função da delimitação das bases de dados e do direcionamento dado ao artigo, este enfoque não recebeu o merecido destaque.

Entende-se que se trata de dois tipos diferentes de originalidade na arte: uma mediada pela excentricidade da percepção e outra pela distorção cognitiva grave.

Freud (1913/1971) evidenciou uma forma de funcionamento peculiar dos processos psíquicos primário (princípio do prazer) e secundário (princípio de realidade) na criatividade artística que se torna profilática, ou seja, previne o perigo do aumento dos conflitos derivado da abnegação de um desejo. A arte ocasiona uma reconciliação entre os dois princípios (prazer e realidade) de maneira peculiar. O artista, como o paciente com esquizofrenia, se afasta de uma realidade insatisfatória para o mundo da imaginação; mas, diferentemente do paciente com esquizofrenia, sabe encontrar 0 caminho de volta do imaginário e, mais uma vez, consegue um firme apoio na realidade. Suas criações, obras de arte, são satisfações imaginárias de desejos inconscientes, que são delineadas de tal forma que são valorizadas pelos homens como reflexos preciosos da realidade. De certa maneira, Freud (1913/1971) asseverava que a arte é a sublimação de um desejo frustrado.

A partir do momento da não existência de um ego para filtrar os conteúdos do inconsciente, o material que emerge é como um magma incandescente, livre, sem encontrar obstáculos, passando de representação em representação, de imagem em imagem dentro de uma passividade transitória, reversível e intencional. Nesse sentido, não se perde totalmente o contato com da realidade, pois essa passividade não se estende a toda psique, não invalida o processo secundário (a consciência que ordena e racionaliza com base no princípio de realidade).

Diante disso, Knafo (2002) esclarece que esse tipo de regressão ao primário deve ser dissociado da sua característica patológica, considerando-se que a capacidade para regressão a serviço do ego é uma precondição para um ego forte. Assim sendo, é importante destacar que as forças regressivas participam da criatividade e permitem frequentes níveis de consciência não usualmente acessíveis para maioria dos adultos.

O estudo de Resende (2001), por meio do Método de Rorschach, um método de avaliação da personalidade, demonstrou dois tipos diferentes de originalidade na produção de artistas e pacientes com esquizofrenia: uma mediada pela excentricidade da percepção e outra pela distorção cognitiva grave. Observou-se também que nos dois grupos tinham várias pessoas com um tipo de processamento 
intelectual sofisticado e, ao mesmo tempo, associado a pensamentos e condutas extravagantes, idiossincráticas e muitas vezes mediadas por elaborações cognitivas aparentemente distorcidas da realidade. Nesse sentido, destacou-se que existia a mesma quantidade de estruturas que denunciavam excentricidade e desagregação do pensamento tanto nos artistas quanto nos pacientes. A diferença foi que as estruturas eficientes, em quantidades muito superiores nos artistas, e estatisticamente significantes, asseguravam o equilíbrio dinâmico entre as estruturas saudáveis e patológicas, o que não ocorreu no grupo de pacientes esquizofrênico, que muitas vezes se destacavam por um funcionamento também exageradamente aberto, flexível com pouca capacidade de diferenciar informações importantes de informações acessórias e pelo pouco contato com realidade.

Diante do que foi exposto a respeito da personalidade do artista, mediante o Método de Rorschach, presume-se novamente que a crença de que a genialidade está relacionada com a loucura - de origem muito antiga, remontando, no mínimo, a Platão e Aristóteles não é de toda infundada. O artista ao ter a capacidade de entrar em contato com seus medos, tristezas e desejos mais profundos, acaba por aproximar-se da loucura e corajosamente desafiá-la para um duelo. Ao ter a liberdade de expressar sua autêntica singularidade acaba por agir com a espontaneidade de um paciente com esquizofrenia que não tem limites e nem vergonha de se expressar. Ao definir uma forma sublime de comunicar com o mundo a sua experiência de vida interior por meio de sua obra, revela uma compreensão mais ampla da experiência humana, demonstra sua capacidade de contato com realidade e de integrar-se ao grupo social que pertence e com a humanidade como um todo.

Entende-se que independente do tipo de originalidade na obra artística, seja ela uma sublimação ou expressão livre de um mundo interno adoecido, a arte resgata o seu criador

No nosso ateliê, a pintura não é entendida como "medium", tem valor próprio,não só para pesquisas referentes ao obscuro mundo interno de esquizofrênico, mas também no tratamento da esquizofrenia.

Atribuímos grande importância à imagem em si mesma. Se o indivíduo que está mergulhado no caos de sua mente dissociada consegue dar forma às emoções, representar em imagens as experiências internas que o transtornam, se objetiva a perturbadora visão que tem agora do mundo, estará desde logo despotencializando essas vivências, pelo menos em parte, de suas fortes cargas energéticas, e tentando reorganizar sua psique dissociada.

A pintura dos esquizofrênicos é muito rica em símbolos e imagens que condensam profundas significações $e$ constituem uma linguagem arcaica de raízes universais. Linguagem arcaica, mas não morta. A linguagem simbólica 
desenvolve-se em várias claves e pautas, transforma-se e é transformadora (SILVEIRA, 2011, p. 1-2).

\section{Referências}

ABRAHAM, A.; WINDMANN, S.; MCKENNA, P.; DAUM, I.; GUNTURKUN, O. Conceptual expansion and creative imagery as a function of psychoticism. Consciousness and cognition, San Diego, v. 14, p. 520-534, 2005.

ABRAHAM, A.; WINDMANN, S.; MCKENNA, P.; GUNTURKUN, 0. Creative thinking in schizophrenia: the role of executive dysfunction and symptom severity. Cognitive neuropsychiatry, London, v. 12, n. 3, p. 235-58, 2007.

ADAD, M. A.; CASTRO, R.; MATTOS, P. Aspectos neuropsicológicos da esquizofrenia. Revista Brasileira de Psiquiatria, São Paulo, v. 22, n. 1, p. 31-34, 2000.

ALENCAR, E. M. L. S. de. Criatividade. Brasília: Editora UnB, 1995.

American Psychiatric Association (APA). Manual diagnóstico e estatístico de transtornos mentais - DSM-IV-TR. 4.ed. Porto Alegre: Ed. Artemed, 2002.

ANDREASEN, N. C. Creativity and mental illness: prevalence rates in writers and their first degree relatives. American Journal of Psychiatry, Arlington, v. 151, p. 1650-1656, 1987.

ANDREASEN, N. C.; CANTER, A. The creative writer: psychiatric symptoms and family history. Comprehensive Psychiatry, New York, v. 29, p. 207-217.

ANDREASEN, N. C.; POWERS, P. S. Creativity and psychosis: an examination of conceptual style. Archives of General Psychiatry, Chicago, v. 32, p. 70-73, 1975.

ARISTÓTELES. Poética. Tradução de Eudoro de Sousa. 5 ed. [S.I.]: Imprensa Nacional, Casa da Moeda, 1998.

BACHNER-MELMAN, R.; DINA, C.; ZOHAR, A. H.; CONSTANTINI, N.; LERER, E.; HOCH, S.; SELLA, S.; NEMANOV, L.; GRITSENKO, I.; LICHTENBERG, P.; GRANOT, R.; EBSTEIN, R. P. AVPRla and SLC6A4 gene polymorphisms are associated with creative dance performance. PLoS Genetics, São Franciso, v. 1, n. 3, p. 41-42, 2005.

BARRANTES-VIDAL, N. Creativity \& Madness revisited from current psychological perspectives. Journal of Consciousness Studies, [S. I.], v. 11, n. 3-4, p. 58-78, 2004.

BARRANTES-VIDAL, N.; LEWANDOWSKI, K. E.; KWAPIL, T. R. Psychopathology, social adjustment and personality correlates of schizotypy clusters in a large nonclinical sample. Schizophrenia Research Amsterdam v. 122, n. 1-3, p. 219-225. No prelo.

BRÜNE, M. Schizophrenia an evolutionary enigma? Neuroscience and Biobehavioral Reviews, New YOrk, v. 28, n. 1, p. 41-53, 2004. 
BURCH, G. S. J.; HEMSLEY, D. R.; PAVELIS, C.; CORR P. J. Personality, creativity and latent inhibition. Europen Journal of Personality, Malden, v. 20, p. 107-120, 2006.

BURCH, G. S. J.; PAVELIS, C.; HEMSLEY, D. R.; CORR, P. J. Schizotypy and creativity in visual artists. British Journal of Psychology, Malden, v. 97, n. 2, p. 177-190, 2006.

CARSON, S. H.; PETERSON, J. B.; HIGGINS, D. Decreased latent inhibition is associated with increased creative achievement in highfunctioning individuals. Journal of Personality and Social Psychology, Washington, v. 85, n. 3, p. 499-506, 2003.

CARSON, S. H.; PETERSON, J. B.; HIGGINS, D. M. Reliability, validity and factor structure of the creative achievement questionnaire. Creativity Research J ournal, [S. I], v. 17, n. 1, p. 37-50, 2005.

CASTELO FILHO, C. O processo criativo: transformação e ruptura. São Paulo: Casa do Psicólogo, 2004.

CRESPI, B.; SUMMERS, K; DORUS, S. Adaptive evolution of genes underlying schizophrenia. Proceedings of the Royal Society of London, Series B - Biological Sciences, London, v. 274, p. 28012810, 2007.

DALGALARRONDO, P. Psicopatologia e semiologia dos transtornos mentais. Porto Alegre: Artes Médicas Sul, 2000.

DOLLINGER, S. J .; URBAN, K. K.; J AMES, T. A. Creativity and openness: further validation of two creative product measures. Creativity Research J ournal, [S. I.], v. 16, n. 1, p. 35-47, 2004.

FISHER, J. E.; MOHANTY, A.; HERRINGTON, J. D.; KOVEN, N. S.; GREGORY, A.; HELLER, W. Neuropsychological evidence for dimensional schizotypy: implications for creativity and psychopathology. Journal of Research in Personality, New York, v. 38, n. 1, p. 24-31, 2004.

FOLLEY, B. S. The cognitive neuroscience of creative thinking in the schizophrenia spectrum: individual differences, functional laterality and white matter connectivity. 2006. $146 \mathrm{f}$. PhD. Thesis (Doctor of Philosophy in Psychology) - Faculty of the Graduate School of Vanderbilt University, Tennessee, 2006.

FOUCAULT, M. Doença mental e Psicologia. Rio de Janeiro: Tempo Brasileiro, 1984.

FREUD, S. Toten y tabu. Obras completas - Tomo II (L. T. Ballesteros e de Torres, Trad.) Madrid: Biblioteca Nueba, 1971.

GESOMINO, R. O. Conceito e imagem na produção do imaginário periférico: um estudo de caso. 2008. 120 f. Dissertação (Mestrado em Artes Visuais) - Escola de Belas Artes, Universidade do Rio de J aneiro, Rio de Janeiro, 2008.

HELLING, I.; OHMAN, A.; HULTMAN, C. M. School achievements and schizophrenia: a case-control study. Acta Psychiatrica Scandinavica, Copenhagen, v. 108, n. 5, p. 381-386, 2003. 
HOYT, S. M. A cognitive style: a relationship between creativity and schizophrenia. Dissertation Abstracts International: Section B: The Sciences and Engineering, Ann Arbor, v. 64, n. 6-B, p. 2950, 2003.

Jamison, K. R. Mood disorders and patterns of creativity in British writers and artists. Psychiatry, Washington, v. 52, p. 125-134, 1989.

KARLSSON, J. Academic achievement of psychotic or alcoholic patients. Hereditas, Landskrona, v. 99, p. 69-72, 1983.

KARLSSON, J. Genetic association of giftedness and criativity with schizophrenia. Hereditas, Landskrona, v. 66, p. 177-182, 1970.

KARLSSON, J. Mental abilities of male relatives of psychotic patients. Acta Psychiatrica Scandinavica, Copenhagen, v. 104, p. 466-468, 2001

LENZENWEGER. M. F. Esquizotipia: considerações teóricas, estrutura latente e o fenótipo expandido. In: MAJ, M.; SARTORIUS, N. (Orgs.). Esquizofrenia. Porto Alegre, Artmed, 2005, p. 307-308.

LIDDLE, P. F.; BARNES, T. R. Syndromes of chronic schizophrenia. British J ournal of Psychiatry, Malden, v. 157, p. 558-561, 1990.

LUDWIG, A. M. Mental illness and creative activity in female writers. American J ournal of Psychiatry, Arlington, v. 151, p. 1650 -1656, 1994.

LUDWIG, A. M. Creative achievement and psychopathology: comparison among professions. American Journal of Psychotherapy, New York, v. 46, p. 330-356, 1992.

MAY, R. Minha busca da beleza. Petrópolis: Editora Vozes Ltda, 1992.

MILLER, G. F.; TAL, I. R. Schizotypy versus openness and intelligence as predictors of creativity. Schizophrenia Research, Amsterdam, v. 93, p. 317-324, 2007.

MONTEIRO, L. DE C.; LOUZÃ, M. R. Alterações cognitivas na esquizofrenia: conseqüências funcionais e abordagens terapêuticas.

Revista de Psiquiatria Clínica, São Paulo, v. 34, n. 2, p. 179-183, 2007.

NETTLE, D. Schizotypy and mental health amongst poets, visual artists, and mathematicians. Journal of Research in Personality, New York, v. 40, n. 6, p. 876-890, 2006.

NETTLE, D. Strong I magination: madness, creativity and human nature. Oxford: Oxford University Press, 2001.

NETTLE, D.; CLEGG, H. Schizotypy, creativity and mating success in humans. Proceedings of the Royal Society of London, Series B Biological Sciences, London, v. 273, p. 611-615, 2006.

O'REILLY, T.; DUNBAR, R.; BENTALL, R. Schizotypy and creativity: an evolutionary connection? Personality and Individual Differences, Oxford, v. 31, n. 7, p. 1067-1078, 2001. 
OTSUKA, K.; SAKAI, A. Haizmann's madness: the concept of bizarreness and the diagnosis of schizophrenia. History of psychiatry, Chalfont St. Giles, v. 15, n. 57, p. 73-8, 2004.

PELBART, P. P. Da clausura do fora ao fora da clausura. São Paulo: Brasiliense, 1989.

PESSOTTI, I. A loucura e as épocas. Rio de Janeiro: Editora 34, 1995.

PORTER, R. Uma história social da loucura. Rio de Janeiro: Jorge Zahar Editor, 1990.

PULL, C. B. Diagnóstico da esquizofrenia: uma revisão. In: MAJ, M.; SARTORIUS, N. (Orgs.). Esquizofrenia. Porto Alegre: Artmed, 2005, p. 13-41.

RAVE, J. Implication of the case of creative people for psychometric. American Psychologist, Washington, v. 57, p. 374-375, 2002.

REUTER, M.; ROTH, S.; HOLVE, K.; HENNIG, J. Identification of first candidate genes for creativity: a pilot study. Brain Research, Amsterdam, v. 1069, n. 1, p. 190-197, 2006.

RICHARDS, R. Creativity and the schizophrenia spectrum: more and more interesting. Creativity Research Journal, [S. I.], v. 13, p. 111-132, 2001.

ROSS, S. R.; LUTZ, C. J.; BAILLEY, S. E. Positive and negative symptoms of schizotypy and the five factor model: a domain and facet level analysis. Journal of Personality Assessment, Burbank, v. 79, p. 53-72, 2002.

RUBINSTEIN, G. Are schizophrenic patients necessarily creative? A comparative study between three groups of psychiatric inpatients. Personality and Individual Differences, Orford, v. 45, p. 806810, 2008.

RYBAKOWSKI, J.; KLONOWSKA, P.; PATRZALA, A.; JARACZ, J. Psychopatologia a kreatywnosc. Psychiatria Polska. Warszawa, v. 40, n. 6, 2006.

SASS, L. A. Schizophrenia, modernism, and the 'creative imagination': on creativity and psychopathology. Creativity Research Journal, [S. I.], v. 13, p. 55-74, 2000-2001.

TERZIAN, A. C. C.; ANDREOLI, S. B.; RAZZOUK, D.; CHAVES, A. C.; MARI, J. J. Fertility and fecundity of an outpatient sample with schizophrenia. Revista Brasileira de Psiquiatria, São Paulo, v. 28, p. 305-307, 2006.

SILVEIRA, N. da. O mundo das imagens. São Paulo, nov. 2011. Disponível em: <http://www. museuimagensdoinconsciente.org.br/pdfs/mundo_imag ens.pdf>. Acesso em: 20 nov. 2011.

Endereços para correspondência

Ana Cristina Resende 
Pontifícia Universidade Católica de Goiás, Departamento de Psicologia - Área IV, Av. Universitária, 1.440, Setor Universitário, CEP 74605-010, Goiânia - GO, Brasil Endereço eletrônico: anacristinaresende@hotmail.com

\section{I rani I racema de Lima Argimon}

Av. I piranga 6681, Prédio 11, 9o andar, CEP 90619-900, Porto Alegre - RS, Brasil Endereço eletrônico: argimoni@pucrs.br

Recebido em: 01/03/2010

Reformulado em: 13/07/2010

Aceito para publicação em: 21/07/2010

Acompanhamento do processo editorial: Adriana Benevides Soares

\section{Notas}

* Doutora em Psicologia Clínica.

**Doutora em Psicologia. 